Available online at www.eccomasproceedia.org

Eccomas Proceedia COMPDYN (2021) 309-317

ECCOMAS

Proceedia
COMPDYN 2021

$8^{\text {th }}$ ECCOMAS Thematic Conference on Computational Methods in Structural Dynamics and Earthquake Engineering M. Papadrakakis, M. Fragiadakis (eds.) Streamed from Athens, Greece, 28 - 30 June 2021

\title{
A DISCRETE-MACRO-ELEMENT-MODEL FOR THE IN-PLANE ANALYSIS OF MASONRY STRUCTURES STRENGTHENED BY FRCMS
}

\author{
P. Zampieri ${ }^{1}$, R. Piazzon ${ }^{1}$, B. Pantò ${ }^{2}$ and C. Pellegrino ${ }^{1}$ \\ ${ }^{1}$ Department of Civil, Environmental and Architectural Engineering, University of Padua, \\ Via Marzolo 9, 35131 Padua, Italy \\ paolo.zampieri@unipd.it-paolo.zampieri@dicea.unipd.it \\ ${ }^{2}$ Department of Civil and Environmental Engineering, Imperial College London \\ London SW72BU, UK \\ b.panto@imperial.ac.uk
}

\begin{abstract}
Recent earthquakes demonstrated the vulnerability of existing and historical masonry constructions. Many strengthening techniques for the seismic retrofitting of these structures have been introduced in the literature. Among these, FRCM strategies, based on the application of fibrereinforced composite materials on the masonry surface through inorganic mortar layers, has become rather popular due to their physic and mechanic compatibility with historical masonries, low invasiveness and capacity to improve both the in-plane and the out of plane masonry behaviour. In this paper, a simplified discrete model, working at the material macroscale, is proposed to simulate the in-plane behaviour of masonry panels strengthened by FRCM systems. The proposed modelling approach is based on the DMEM model, whose calibration is enhanced to encompass the properties of the externally bonded strengthening system. According to the proposed strategy, the masonry support and the FRCM layers are simulated by an equivalent homogeneous material, discretised by a mesh of shear-deformable articulated quadrilaterals interacting along their edges by means of $2 D$ unilateral cohesive-friction links. The model is implemented in OpenSees and validated by simulating experimental shear-diagonal tests, available in literature.
\end{abstract}

Keywords: FRCM, Composite material, Masonry structures, DMEM, in-plane behaviour, nonlinear analysis.

ISSN:2623-3347 (C) 2021 The Authors. Published by Eccomas Proceedia. Peer-review under responsibility of the organizing committee of COMPDYN 2021. doi: $10.7712 / 120121.8484 .19046$ 


\section{INTRODUCTION}

The numerical description of the mechanical behavior of masonry elements strengthened with externally bonded systems, such as Fabric Reinforce Polymer (FRP) or Fabric Reinforced Cementitious Matrix (FRCM) systems, represent a current complex task and requires complex mathematical models due to the non-linearity and anisotropy of masonry and the non-linear interaction between the reinforcement and the masonry support [1,2]. An effective modelling approaches to simulate unreinforced and reinforced masonry panels are represented by mesoscale finite element models [3-7] which explicitly simulate masonry, brick-block, units and mortar joints. According to these strategies, nonlinear zero-thickness interfaces describe both the behaviour of mortar joints and the masonry-reinforcement layer. However, these models require high computational costs; especially for external reinforced masonry elements where the matrix, the reinforce and the interfaces are detailed represented [8]. Consequently, these methods are not suitable for engineering applications.

Then the challenging problem of the scientific community is to simulate the complex mechanical behavior of unreinforced/strengthened masonry constructions with a limited computational cost and with sufficient accuracy. Is the case of simplified continuum finite element models where the masonry is represented as an equivalent homogenized continuum material $[9,10]$. Simplified structural macromodels aiming at drastically reduce the computational effort by describing each structural element through a single computational element (macro-element) or a coarse mesh of them, are largely used both in engineering practice and research $[11,12]$. Two of the most popular structural macro-models are represented by Equivalent Frame Model (EFM), in which the masonry building is represented by an equivalent nonlinear frame structure constituted by nonlinear beam element and rigid offsets $[13,14]$, and the Macro-Element Model (DMEM), in which masonry panels are represented by sheardeformable 2D macro-elements interacting by discrete nonlinear interfaces [15-18]. The latter model guarantees a geometrically consistent description of masonry panels thanks to its 2D kinematics also allowing a more accurate simulation of the interaction between masonry panels and beam/column elements [19].

In this paper, a new simplified numerical strategy for the simulation of the in-plane FRCM strengthened masonry walls is proposed. This approach is based on the subdivision of a FRCMstrengthened masonry panel in a macro-mesh of shear-deformable elements interacting by discrete interfaces, according to the DMEM modeling strategy. Each interface is composed of a set of 2D links which describe the flexural/axial and shear behavior of masonry and the reinforcement layer. The proposed model is applied to simulate some experimental diagonal-compression tests performed on unreinforced and FRCM-strengthened masonry panels. The comparisons are presented in terms of load-force capacity curves and distribution of damage at the failure of the panel. The results of the analyses confirmed that the proposed model is able to simulate the response of the specimens with a satisfactory level of accuracy.

\section{DESCRIPTION OF THE NUMERICAL STRATEGY}

According to the proposed strategy, the masonry panel is subdivided in a mesh of sheardeformable panels (shear panel) that simulate the shear deformability of masonry portion represented. It is worth pointing out that, contrary to mesoscale approaches, the mesh discretization is not directly related to the brick-masonry arrangement which is taken into account by the calibration procedures of the interfaces. Following the DMEM approach, each shear panel can be described by an articulated 
quadrilateral with rigid edges which are used to connect the interface links allowing the interaction between the shear panel and the adjacent elements. . Each interface (horizontal and vertical interfaces in Figure 1) is constituted by $m$ nonlinear 2D links which model the flexural and shear-sliding behaviours of masonry and their coupling.
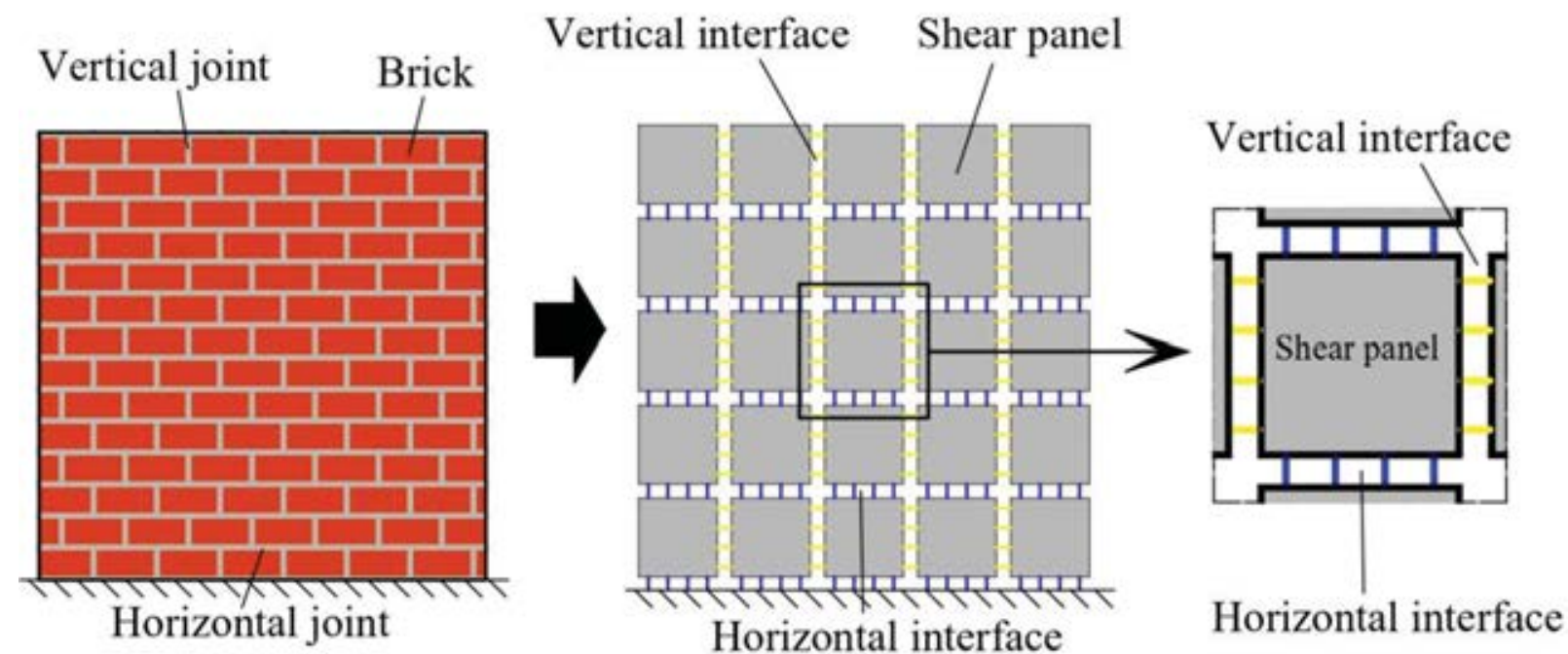

Figure 1 Real masonry wall (left); numerical representation with discrete elements (center); Single discrete element (right)

Each interface link, as depicted in Figure 2, is constituted by two one-dimension springs arranged in-series. One spring is oriented along the direction perpendicular to the connected panel edge (normal spring) and one spring is parallel to the edge (shear spring). The normal spring simulating the masonry axial behaviour is character by the normal displacement $U_{N}$ and force $F_{N}$ while the shear spring is characterized by the shear displacement $U_{T}$ and force $F_{T}$. The two springs behaviour is coupled according to the Mohr coulomb failure criterion, based on the friction coefficient $(\mu)$ and the cohesive force $\left(F_{0}\right) . K_{N, 0}$ and $K_{T, 0}$ are the initial values of the stiffness respectively in normal and in tangential direction.
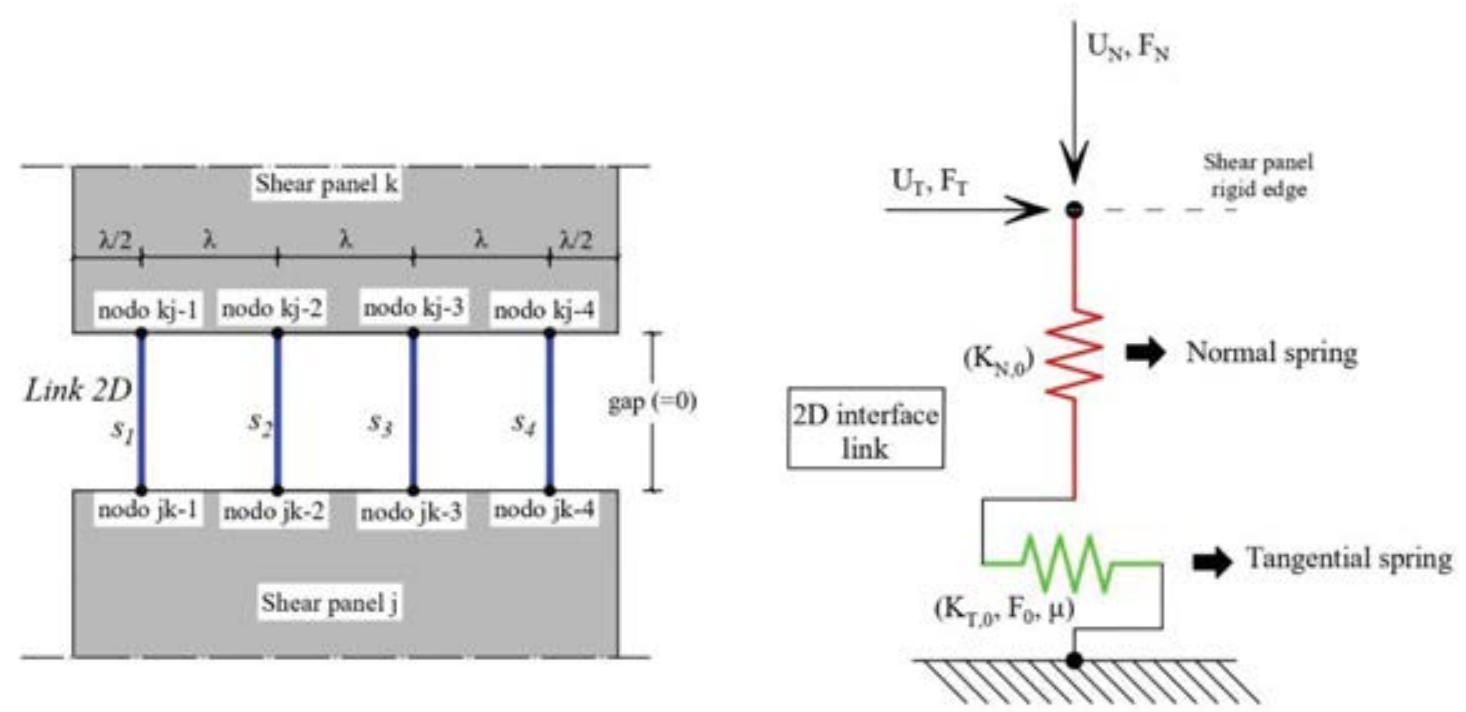

Figure 2 Discrete element interface with representation of all the nodes that are connected with 2D links (left); single 2D link numerical representation (right) 


\section{MODEL CALIBRATION}

\subsection{Calibration of the 2D masonry links}

The constitutive law of the normal spring in compression is characterized by a parabolic relationship until the peak-strength, followed by a linear-softening and a residual strength (Figure 3a). The tensile behavior is linear elastic until the material strength after a linear softening is considered. When the displacement $U_{N, t u}$ is reached the material is considered cracked and the residual tensile strength is equal to zero. This model considers the masonry material in two conditions: cracked and uncracked considering two different force-displacement curves as shown in Figure $3 \mathrm{~b}$ and in Figure 3c.

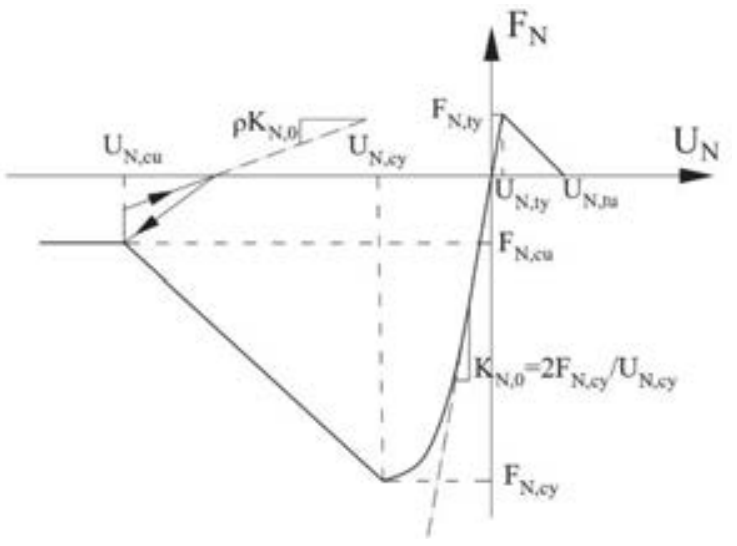

(a)

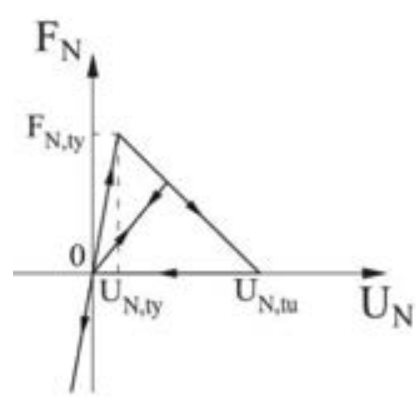

(b)

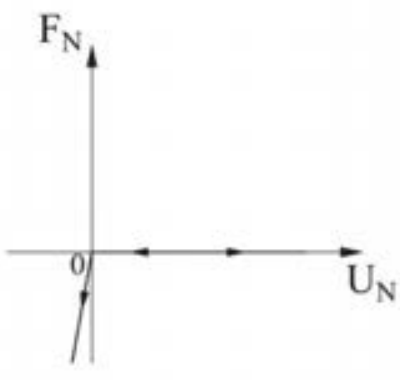

(c)

Figure 3 Constitutive law of the normal spring: backbone curve in compression and tension and unload-reload rules in compression; unloading behaviour in tension before cracking (b); behaviour in tension after material cracked (c)

The initial stiffness $K_{N, 0}$ calibration is obtained assigning to each link the axial rigidity of the corresponding masonry strip. The same process is applied to assign to the normal material the compression and tensile yielding force $F_{N, c y}, F_{N, t y}$. In the case of the calibration of the interface link that connect two shear panels we have:

$$
\begin{aligned}
K_{N, 0} & =\frac{E \cdot \lambda \cdot s}{h_{\text {infl,tot }}} \\
F_{N, c y} & =s \cdot \lambda \cdot \sigma_{c} \\
F_{N, t y} & =s \cdot \lambda \cdot \sigma_{t}
\end{aligned}
$$

Where: $E$ is the Young modulus of the masonry, $\lambda$ is the distance between two 2D links, $\mathrm{s}$ is the thickness of the represented masonry panel, $h_{\text {infl,tot }}$ is the sum of the two semi length of the adjacent shear panels, measured in the direction orthogonal to the direction of the interface; $\sigma_{c}$ and $\sigma_{t}$ are the compressive and tensile yielding stresses. The compressive yielding displacement $\mathrm{U}_{\mathrm{N}, \mathrm{cy}}$ and the tensile yielding displacement $U_{\mathrm{N}, \mathrm{ty}}$ are calculated considering rigidity, force and the constitutive law.

The shear spring are characterized by an elasto-plastic constitutive law with linear softening (Figure 4), governed by a Mohr Coulomb yielding surface. The sliding occurs when the force in the direction tangential reaches its limit value, $\mathrm{F}_{\text {lim, }}$, calculated as reported in Eq. (4) in which $\mu$ is the friction coefficient, $\mathrm{F}_{\mathrm{N}}$ is the force acting in the normal spring of the $2 \mathrm{D}$ link and $F_{0}=c \cdot \lambda \cdot s$, and $c$ is the cohesive strength of the masonry.

$$
F_{T, \lim }=\mu \cdot F_{N}+F_{0}
$$



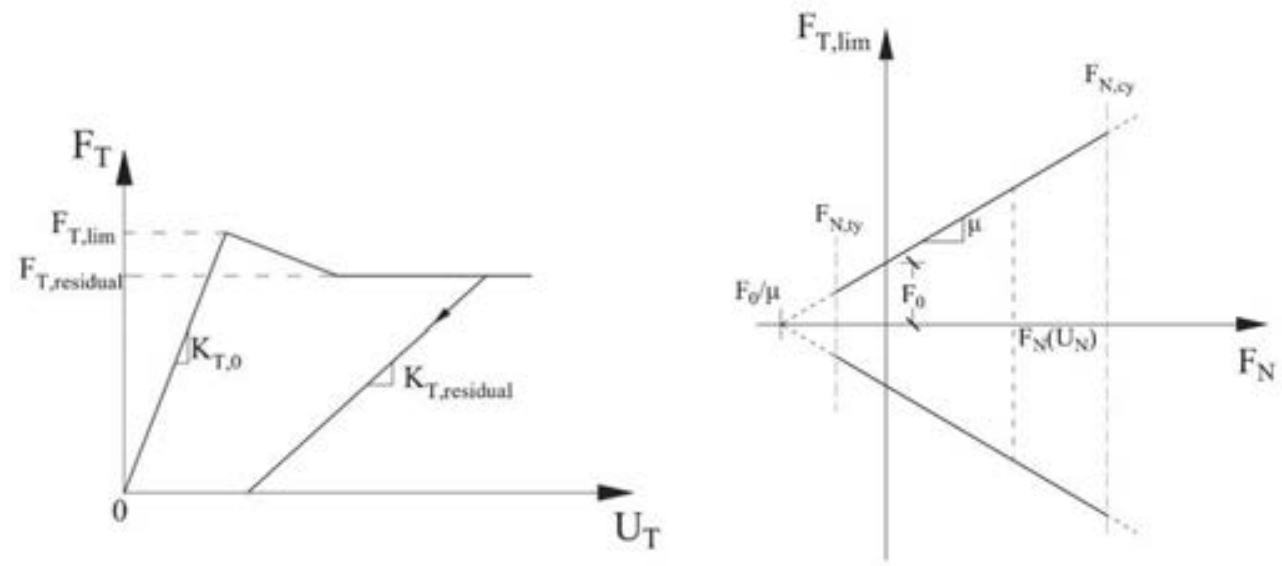

Figure 4 Shear behaviour of the 2D link (left); influence of the normal force agent in the 2D link to the limit shear force $\mathrm{F}_{\mathrm{T}, \mathrm{lim}}$ (right)

\subsection{Calibration of FRCM strengthening system}

The FRCM matrix is represented by an additional 2D links in parallel with the 2D masonry links and distributed along the panel edge with the same interval. The shear spring of the reinforcement link is characterized by the same constitutive law of the shear spring of the masonry links (figure $3 \mathrm{~b}$ ), calibrated considering the experimental shear strength of the mortar layer or the reinforcement [2125]. The normal spring is characterized by an arbitrary multi-linear force-slip $\left(\sigma-U_{N}\right)$ relationship in tension, calibrated according to the force-slip relationship determined by a shear lap test [21-25] (Figure 5), and zero compression strength.

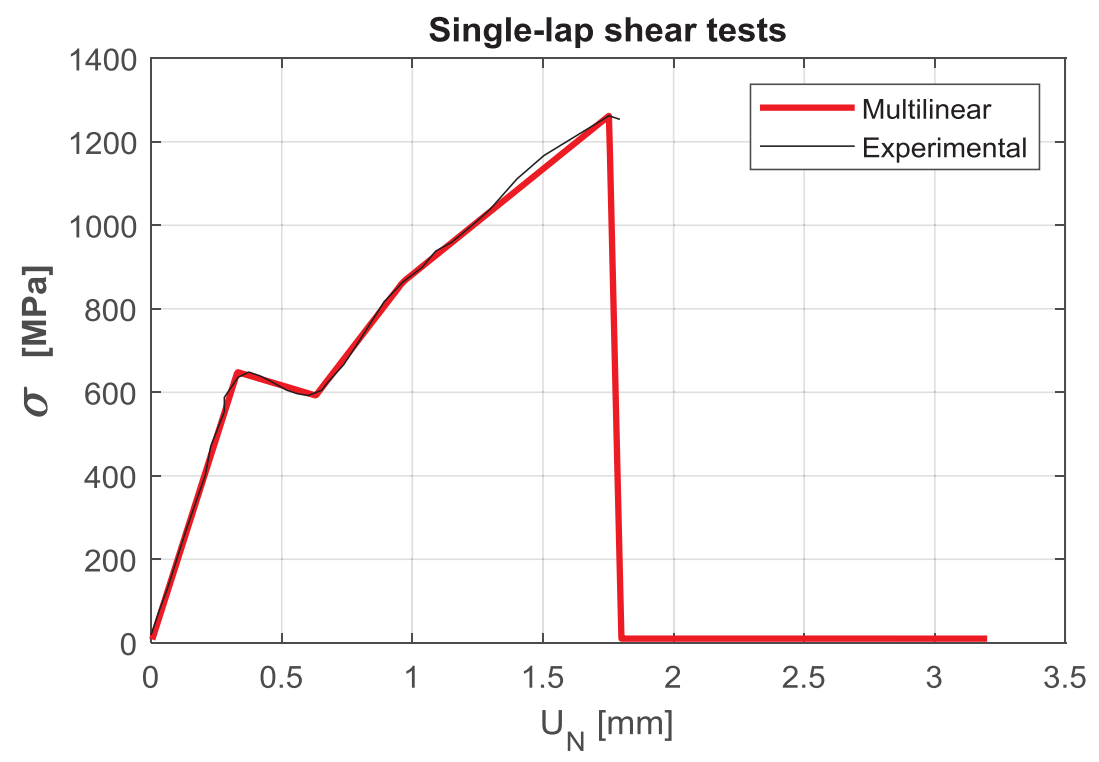

Figure 5 Comparison between the experimental result of the single shear lap test and the behaviour of the multilinear material to assign to the element that represent the fibers. In the graph $\sigma$ stands for the tension in the fibers area, without the matrix; $\mathrm{U}_{\mathrm{N}}$ is the sliding between fibers and matrix.

\section{NUMERICAL SIMULATIONS OF DIAGONAL COMPRESSION TESTS FRCM STRENGHTENED MASONRY WALLET}

This case study considers the results of the diagonal compression test brick masonry walls, executed experimentally [20]. The wall tested in laboratory $\left(129 \times 129 \times 25 \mathrm{~cm}^{3}\right)$ were built using standard clay bricks and hydraulic lime-based mortar for the bed joints. 
The tests are executed at displacement control, applying the vertical load along the principal diagonal direction of the square panel. Deformations along the two principal directions were recorded by using linear potentiometric transducers. The results are reported using $\tau-\gamma$ diagrams, considering $\gamma$ as the sum of the deformations along the principal diagonals $\left(\varepsilon_{c}, \varepsilon_{t}\right) ; \tau$ is the tangential stress calculated as $\tau=P / A_{d}$, in which $P$ is the load applied and $A_{d}$ is the section of the wall measured on the principal diagonal of the specimen. These tests are reproduced numerically with a mesh 10x10 of discrete elements (Figure 6).
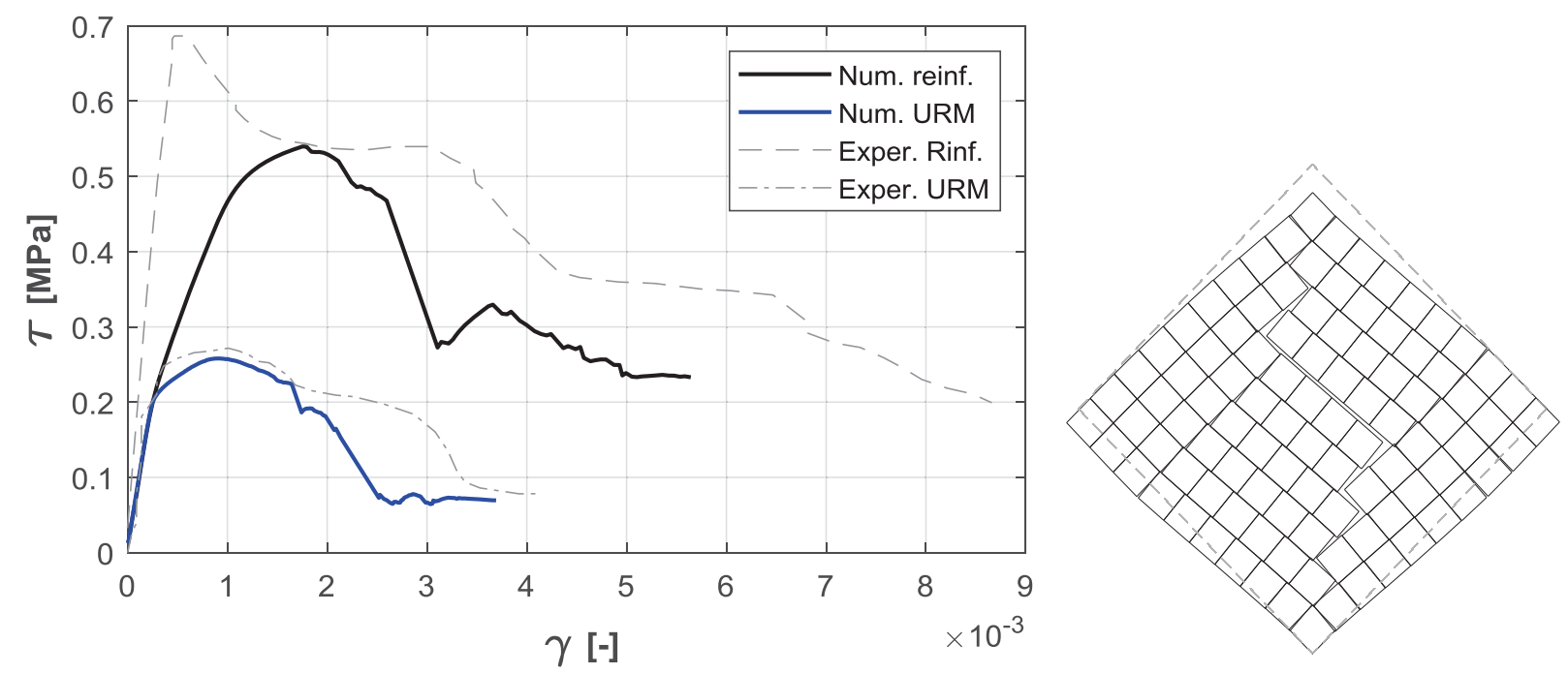

Figure 6 Comparison between the experimental and numerical results (left) and deformed shape registered after the first peak in the numerical strengthened wall, considering an amplification factor of 50 (right)

\section{DISCUSSION OF THE RESUTS}

The proposed procedure well simulates the nonlinear behavior of the URM wall in terms of initial stiffness, peak load and residual load. Moreover, observing the numerical deformation, is evident the formation of a single diagonal cracking. This collapse mechanism reflects the failure mode experimentally observed.

In the case of the strengthened panel, some differences are observed between the experimental and numerical capacity curves, mainly in the peak-strength phase. However, the global trend of the experimental curve is reproduced with a satisfactory approximation, moreover the failure mechanism is well reproduced (Figure 6). Analyzing the stress and deformations of the Links representing masonry, mortar matrix and fibers, it is possible to determine the failure points of each element, as reported in Figure 7. The first part of the curve corresponds to the linear part, in which masonry and matrix aren't cracked. In this phase the tensile stresses in the fibers are lower than $200 \mathrm{MPa}$. The first peak corresponds to the cracking of the masonry in the central part of the panel, followed by the cracking of the matrix along the loaded diagonal. After this point, the external force decreases due to opening of the diagonal crack, that can be clearly seen in the deformed shape. The tensile deformations in the cracked interfaces continue to increase, allowing the fibers to increase tensile deformations and stresses, which result much higher than those registered during the uncracked phase. The second increase in strength is due indeed to the contribution of the elements that represents the fibers. The second peak corresponds to the yield of the fibers in the central part of the panel. 


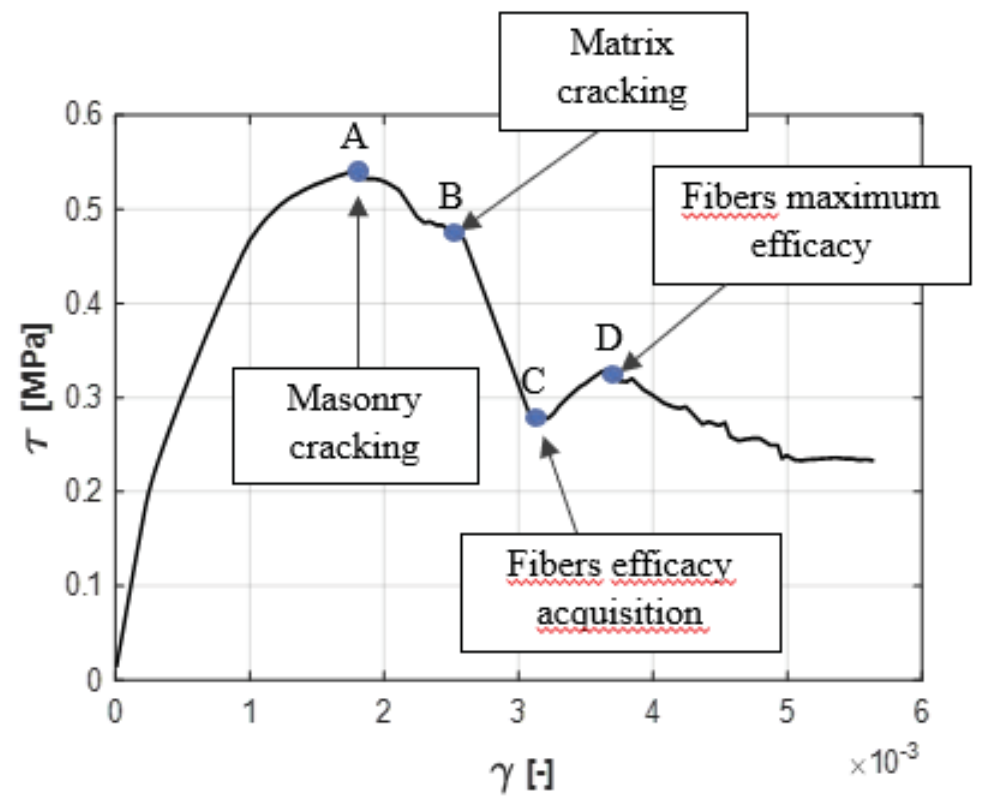

Figure 7 Numerical result with the indication of collapse of every material

\section{CONCLUSION}

This paper introduces a simplified model for the simulation of the nonlinear in-plane response of masonry panels strengthened by FRCM systems. The masonry is described by a mesh of discrete elements able to simulate the main collapse modes of masonry material. The FRCM reinforcement is simulated by a simple and efficient method. The calibration of the model is immediate and based on the materials parameters. As a numerical case study, a diagonal compression test has been simulated. The comparison between experimental and numerical results highlights the efficiency of the method in reproducing the global collapse modalities of the mixed system constituted by the masonry and the reinforcement. In the numerical simulation, according to the experiments, the matrix contributed to the first peak of the capacity curve while the contribution of the fibers resulted predominant in the post-peak phase where the capacity curve showed a second peak, after a main diagonal crack was developed.

\section{REFERENCES}

[1] Nicolò Simoncello, Paolo Zampieri, Jaime Gonzalez-Libreros, Carlo Pellegrino, 2019. Experimental behaviour of damaged masonry arches strengthened with steel fiber reinforced mortar (SFRM), Composites Part B: Engineering, Volume 177,.

[2] Paolo Zampieri, Nicolò Simoncello, Jaime Gonzalez-Libreros, Carlo Pellegrino, 2020. Evaluation of the vertical load capacity of masonry arch bridges strengthened with FRCM or SFRM by limit analysis, Engineering Structures, Volume 225.

[3] Macorini, L. and Izzuddin, B.A., 2011. A non- linear interface element for 3D mesoscale analysis of brick- masonry structures. International Journal for numerical methods in Engineering, 85(12), pp.1584-1608.

[4] Simone Tiberti, Gabriele Milani, 2020. Fast brick-based homogenized limit analysis for inand out-of-plane loaded periodic masonry panels, Computers \& Structures, Volume 231. 
[5] R. Gagliardo, F.P.A. Portioli, L. Cascini, R. Landolfo, P.B. Lourenço, 2021. A rigid block model with no-tension elastic contacts for displacement-based assessment of historic masonry structures subjected to settlements, Engineering Structures, Volume 229.

[6] M. Rossi, C. Calderini, B. Di Napoli, L. Cascini, F. Portioli, 2021. Structural analysis of masonry vaulted staircases through rigid block limit analysis, Structures, Volume 23.

[7] Bertolesi E, Milani G, Casolo S, 2018. Homogenization towards a mechanistic rigid body and spring model (HRBSM) for the non-linear dynamic analysis of 3D masonry structures. Meccanica 53(7):1819-1855

[8] G.P. Lignola, A. Bilotta, F. Ceroni, 2019.Assessment of the effect of FRCM materials on the behaviour of masonry walls by means of FE models, Engineering Structures, Volume 184, , Pages 145-157.

[9] Cavalagli, N., Cluni, F., Gusella, V. 2011. Strength domain of non-periodic masonry by homogenization in generalized plane state, European Journal of Mechanics, A/Solids

[10] Jacopo Scacco, Bahman Ghiassi, Gabriele Milani, Paulo B. Lourenço, 2020. A fast modeling approach for numerical analysis of unreinforced and FRCM reinforced masonry walls under out-of-plane loading, Composites Part B: Engineering, Volume 180.

[11] Aşıkoğlu, A., Vasconcelos, G., Lourenço, P.B. and Pantò, B., 2020. Pushover analysis of unreinforced irregular masonry buildings: Lessons from different modeling approaches. Engineering Structures, 218, p.110830.

[12] Maio, R., Ferreira, T.M., Estêvão, J.M., Pantò, B., Caliò, I. and Vicente, R., 2020. Seismic performance-based assessment of urban cultural heritage assets through different macroelement approaches. Journal of Building Engineering, 29, p.101083.

[13] Lagomarsino S, Penna A, Galasco A, Cattari S, 2013. Tremuri program: an equivalent frame model for the nonlinear seismic analysis of masonry buildings. Eng Struct 56:17871799.

[14] E. Quagliarini, G. Maracchini, F. Clementi, 2017.Uses and limits of the Equivalent Frame Model on existing unreinforced masonry buildings for assessing their seismic risk: A review, Journal of Building Engineering, Volume 10.

[15] Caliò, M. Marletta, B. Pantò, 2012. "A new discrete element model for the evaluation of the seismic behaviour of unreinforced masonry buildings", Engineering Structures 40, 327 338.

[16] Pantò, B., Caliò, I. and Lourenço, P.B., 2018. A 3D discrete macro-element for modelling the out-of-plane behaviour of infilled frame structures. Engineering Structures, 175, pp.371-385..

[17] Penna A, Lagomarsino S, Galasco A, 2014. A nonlinear macroelement model for the seismic analysis of masonry buildings. Earthq Eng Struct Dyn 43(2):159-179

[18] Minga, E., Macorini, L., Izzuddin, B.A. and Calio, I., 2020. 3D macroelement approach for nonlinear FE analysis of URM components subjected to in-plane and out-ofplane cyclic loading. Engineering Structures, 220, p.110951.

[19] Marques, R. and Lourenço, P.B., 2014. Unreinforced and confined masonry buildings in seismic regions: Validation of macro-element models and cost analysis. Engineering Structures, 64, pp.52-67.

[20] A. Incerti, A.R. Tilocca \& A. Bellini, 2020. "In-plane behaviour of FRCMstrengthened masonry panels", Brick and Block Masonry -From Historical to Sustainable Masonry - Kubica, Kwiecień \& Bednarz (eds) (c) Taylor \& Francis Group, London, ISBN 978-0-367-56586-2 
[21] A. Bilotta, F. Ceroni, E. Nigro, M. Pecce, 2017. "Experimental tests on FRCM strengthening systems for tuff masonry elements", Construction and Building Materials, Volume 138, Pages 114-133.

[22] A. Bellini, S. K. Shahreza, C. Mazzotti, 2019. "Cyclic bond behavior of FRCM composites applied on masonry substrate", Composites Part B: Engineering, Volume 169, Pages 189-199.

[23] A. Bellini, M. Bovo, C. Mazzotti, 2019. "Experimental and numerical evaluation of fiber-matrix interface behaviour of different FRCM systems", Composites Part B: Engineering, Volume 161, Pages 411-426.

[24] A. Tilocca, A. Incerti, A. Bellini, M. Savoia, 2019. "Influence of Matrix Properties on FRCM-CRM Strengthening Systems". Key Engineering Materials. 817. 478-485. 10.4028/www.scientific.net/KEM.817.478.

[25] Luisa Rovero, Stefano Galassi, Giulia Misseri, 2020. Experimental and analytical investigation of bond behavior in glass fiber-reinforced composites based on gypsum and cement matrices, Composites Part B: Engineering, Volume 194. 